\title{
Managing Social Performance: A Case of Microfinance
}

\author{
Muamer Halilbasic, Kenan Crnkic \\ University of Sarajevo, Sarajevo, Bosnia and Herzegovina
}

\begin{abstract}
Global financial crises might and should be recognized as a potential chance to introduce changes in managing our business, both in financial and other important private and/or public sectors. The prevailing opinion is that a lack of corporative social responsibility is one of the major reasons that lead to global crises occurrence. Nowadays, it is crucial to use the experiences of other industries and sectors which from their very beginning managed to balance finance and social goals at the same time. Microfinance sector is exactly one such sector. This paper is organized as follows: First, we give some overview of different approaches to measuring social performance of microfinance institutions. In this part of the paper we also accent the specifics of microfinance institutions-management within the context of double bottom line. In the second part we focus our analysis on practical implementation of “double bottom line management” in Prizma MCO, one of the world pioneers in social performance management, by using their revolutionary poverty scorecard system. Then, we analyze how these social performance data are used in decision-making and how it affects overall performance of the organization. The paper is finished with some conclusions and lessons learned.
\end{abstract}

Keywords: social performance management, microfinance, scorecard

\section{Introduction}

Global financial crises might and should be recognized as a potential chance too in the way that we start, having analyzed the lessons learned and the causes of its occurrence, to introduce changes in managing our business, both in financial and other important private and/or public sectors. The prevailing opinion is that a lack of corporative social responsibility and inability of its connection to the most possible extent with fundamental financial parameters of business operation is the one of the major reasons that lead to global crises occurrence. Nowadays, more than ever before, it is crucial to use the experiences of other industries and sectors that have had from their very beginning, in theoretical and applicative sense, clear and undoubtedly set up standards relative to balancing these, at the first sight, confronting concepts—-financial and social performances, and that have showed and proved in up-to-date work that it is possible to achieve both goals at the same time, that none of them excludes other one; On the contrary, they are two sides of a single and the same coin which create in a long run synergy, stability and extraordinary performances even at the time of the biggest crises as this current one is.

\footnotetext{
Muamer Halilbasic, Ph.D., Department of Economics, Sarajevo School of Economics and Business, University of Sarajevo. Kenan Crnkic, Ph.D., Department of Management and Organization, Sarajevo School of Economics and Business, University of Sarajevo.

Correspondence concerning this article should be addressed to Muamer Halilbasic, Trg Oslobodjenja-Alija Izetbegovic 1, 71 000, Sarajevo, Bosnia and Herzegovina. E-mail: muamer.halilbasic@efsa.unsa.ba.
} 
Microfinance sector is exactly one such sector.

The real power of microfinance lies in its potential to combine financial sustainability with meeting social goals. MFIs regularly include this ideal of achieving the "double bottom line” of financial and social performance in their mission statements. Until recently, however, the social dimension of MFIs work has been highly neglected in training, researching and reporting. Part of the reason for this lies in the conception of social performance primarily in terms of impact, that is "change in target client well-being that can be attributed to the microfinance intervention”. This implies that reporting on social performance requires very complex and careful research by specialists and involves substantial resources and time. Perhaps more important is that, according to this view, social reporting is a kind of ad-hoc exercise that does not provide timely information to management, and does not contribute to better alignment of MFIs products with their clients' needs.

A breakthrough in research on MFIs social performance was made in the last few years with several important initiatives that attempt to integrate the assessment of social performance into regular management systems. These initiatives view social performance not exclusively through the end-result but also through the process of achieving it. In this paper, we will first give a short overview of different dimensions of social performance and the main efforts that has been made in last several years to develop common reporting format. We will then focus our analysis on how the results of these researches can be practically implemented, using the example of Prizma MCO. We will also attempt to answer questions such as: What are the main obstacles in the process? What are the costs and benefits, as well as the lessons learned?

\section{Social Performance Assessment}

According to Drucker (2007, p. 38), the modern organization exists to provide a specific service to society. It therefore has to be in society. It has to be in a community, has to be a neighbor, and has to do its work within a social setting. But also, it has to employ people to do its work. Its social impacts inevitably go beyond the specific contribution for which it exists.

Corporate social responsibility (CSR), also known as corporate responsibility, corporate citizenship, responsible business, sustainable responsible business, or corporate social performance, is a form of corporate self-regulation integrated into a business model (Wood, 1991). Ideally, CSR policy would function as a built-in, self-regulating mechanism whereby business would monitor and ensure its adherence to law, ethical standards, and international norms. Business would embrace responsibility for the impact of their activities on the environment, consumers, employees, communities, stakeholders and all other members of the public sphere. Furthermore, business would proactively promote the public interest by encouraging community growth and development, and voluntarily eliminating practices that harm the public sphere, regardless of legality. Essentially, CSR is the deliberate inclusion of public interest into corporate decision-making, and the honoring of a triple bottom line: people, planet, and profit.

There is no doubt that insisting on financial sustainability was of crucial importance for the success of microfinance institutions in the last few decades. Financial sustainability has helped MFIs move from being entirely dependent upon donor grants and ensured access to investment funds. However, financial sustainability and growth do not automatically ensure a substantial increase in the outreach to poor and very poor people. More importantly, it does not ensure that client-level benefits are realized. To be accountable to the donors, MFIs 
should be able to report whether they are achieving their social missions or drifting away from them. It can also help MFIs lower the drop-out rate and reduce costs.

The work on social performance has gained momentum in the last several years with few separate initiatives such as CERISE ${ }^{1}$, Imp-Act Consortium ${ }^{2}$, CGAP ${ }^{3}$ that attempt to integrate social performance into regular management systems and day-to-day operations of MFIs. In order to coordinate different initiatives and eventually come up with a common reporting format, a special network called the Social Performance Task Force (SPTF) is created. Members of this network agreed on the definition of social performance as "effective translation of an institution's social goals into practice in line with accepted social values” (Sinha, 2006, p. 5). As oppose to impact assessment, where the end result is what matters, this definition of social performance emphasizes the necessity to look at the entire process that has to be anchored in the institution's mission and systematically leads to changes in the client's status.

Different steps in the process of achieving change are presented in Figure 1. The process starts with the analysis of the institution's mission, social goals and performance objectives. Does the institution have a social mission? Are its social goals clearly defined and aligned with its social mission? Does the MFI have SMART social objectives related to its mission?

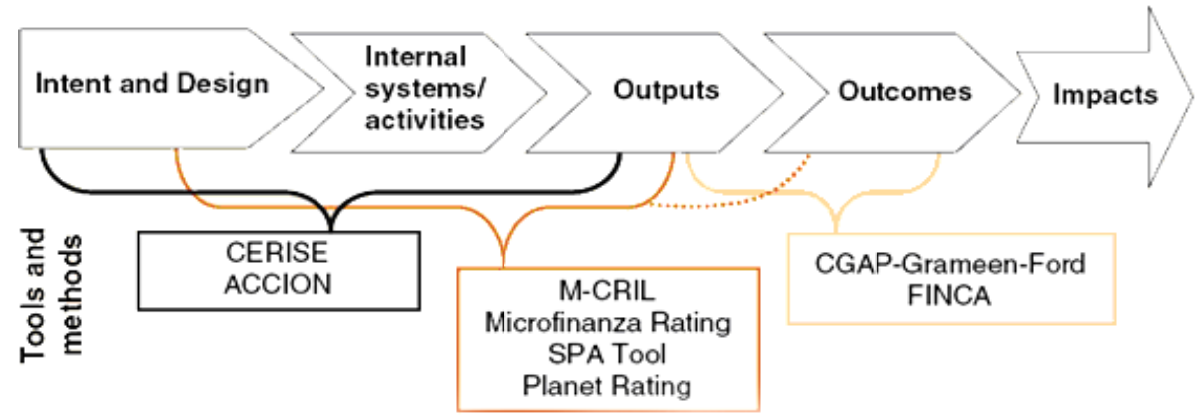

Figure 1. Dimensions of social performance. Source: Hashemi (2007).

This obviously raises an important question. Is it possible to agree on certain generic values that apply to all MFIs? This is necessary to enable direct comparison and "benchmarking" across various contexts and models. The SPTF believes that, while each MFI has its own mission and model, there are certain generic social values that apply to all MFIs. These include improving the lives of poor and excluded clients and widening the range of opportunities for the communities. To create this value, social objectives of an MFI may include ${ }^{4}$ :

- Sustainably serving an increasing number of poor and excluded people by expanding and deepening the outreach to poorer people;

- Improving the quality and appropriateness of financial services through the systematic assessment of target clients' specific needs;

- Creating benefits for microfinance clients, their families and communities to improve the access to social

\footnotetext{
${ }^{1}$ For detailed insight in this initiative you can go on web page: http://www.cerise-microfinance.org/homeuk.htm

2 For more information on this initiative go on web page: http://www2.ids.ac.uk/impact/

${ }^{3}$ More information on this initiative you can find on the web page: http://www.cgap.org/p/site/c/

${ }^{4}$ This is part of the common definition (and social value language) of social performance agreed upon by the Social Performance

Task Force at the March 2005 meeting in Paris.
} 
capital, social links, assets, income and services, to reduce their vulnerability, and meet their basic needs;

- Improving the social responsibility of the MFI toward its employees, its clients, and the community it serves.

The second step of the impact pathway includes the assessment of whether the institution's internal systems and activities are appropriate and aligned with the achievement of its declared social objectives. Is the progress toward social objectives regularly monitored and reported? Does the institution behave responsibly in relation to its clients, staff, community, and environment?

The next step in the process regards the output. Is institution reaching its target clients-how many of them come from remote rural and underdeveloped areas, how many live below the poverty line or do not have access to formal financial services? Are products designed to meet clients' needs and are they in line with their capacities What is the drop-out rate, is the client indebtedness tracked, etc..

The fourth step is about outcome achieved. Are the clients improving their economic and social performance? What is the contribution to MDGs or the employment generation? The final step in the process is related to the impact — establishing causality between the program participation and improvements in the clients' condition.

Although the impact pathway is presented as an arrow that points in one direction, there is an iterative flow of information on the achieved outcome (represented by the dotted line in Figure 1) feeding back into decision-making that helps improve the performance and practice. Only in this way can an effective social performance management be developed.

Various social performance tools developed within distinct initiatives focus on different steps or dimensions of social performance (see Figure 1$)^{5}$. Some tools, such as CERISE, led by availability of information focus on internal systems and organizational processes to determine whether institutions have the means in place to attain their social objectives. For others, such as CGAP, Grameen, Ford Foundation, the ultimate proof of whether social missions are achieved depends on client-level information. Whether institutions that are claiming being socially responsible, are reaching target clients, how appropriate are their services, and whether these clients are experiencing positive changes in their lives. Some specialized rating agencies beside credit rating are also introducing social ratings.

To bridge the gap in microfinance reporting between institutional and client-level information, the SPTF developed a common reporting format for social performance reporting that includes both organizational and client-level indicators ${ }^{6}$. The emphasis is on indicators that are conceptually clear, simple, practical, cost-effective, statistically rigorous, and comparable across countries. In creating the common reporting format, the taskforce is acknowledging flexibility in what institutions choose as their social goals, what tools they use to assess progress on them, and what indicators they report on.

\section{Microfinance in Bosnia and Herzegovina}

In the last ten years, growth of Bosnian-Herzegovinian microfinance sector was extraordinary. From 1999 to 2008, the number of active clients has increased more than tenfold, from 25 to around 390 thousand. In the same period, portfolio outstanding has increased from 25 to almost 800 million \$. Noticeable was also growth of the

\footnotetext{
${ }^{5}$ For more information on different initiatives see Hashemi (2007) or SEEP (2007).

${ }^{6}$ Detail specification you can find at http://www.microfinancegateway.org/content/article/detail/56418
} 
size of average microcredit organization (MCO). The average asset has increased by 20 times and average number of active clients by fifteen times (see Table 1).

Table 1

Growth of MFI Sector in BiH

\begin{tabular}{lcrrr}
\hline \multicolumn{1}{c}{ Indicator } & \multicolumn{3}{c}{ Year } \\
\cline { 2 - 5 } & \multicolumn{1}{c}{1999} & 2002 & \multicolumn{1}{c}{2006} & 2008 \\
\hline Number of active clients & 25,421 & 73,227 & 201,667 & 392,700 \\
Average number of active clients & 2,311 & 6,657 & 16,805 & 35,700 \\
Portfolio outstanding (million \$) & 24,635 & 82,597 & 486,445 & 783,602 \\
Average portfolio outstanding (million \$) & 2,239 & 7,508 & 37,418 & 71,236 \\
Average assets (million \$) & 2,737 & 8,416 & 46,508 & 77,235 \\
Average AROE (\%) & -3.0 & 21.9 & 13.3 & 18.4 \\
Average AROA (\%) & -3.6 & 6.1 & 3.7 & 3.5 \\
Operational efficiency (\%) & 26 & 19 & 21 & 22 \\
Costs per client (\$) & 508 & 372 & 243 & 455 \\
\hline
\end{tabular}

Note. Source: AMFI (2009).
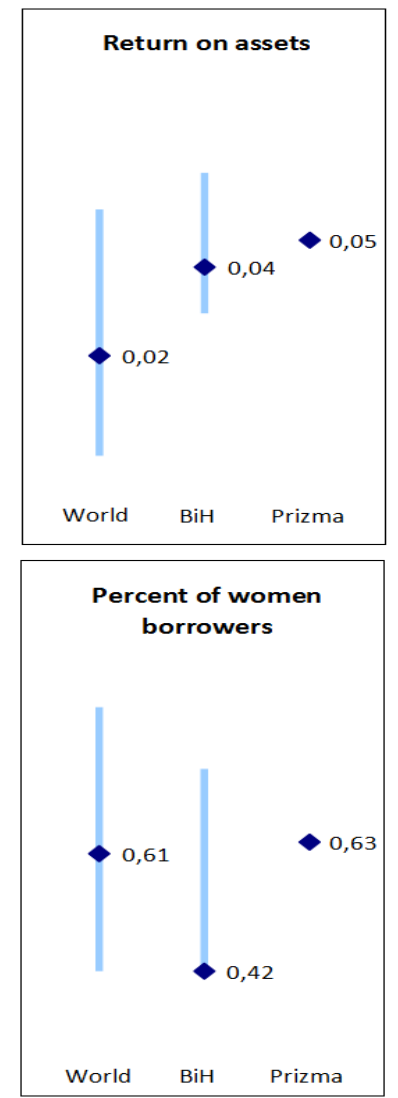
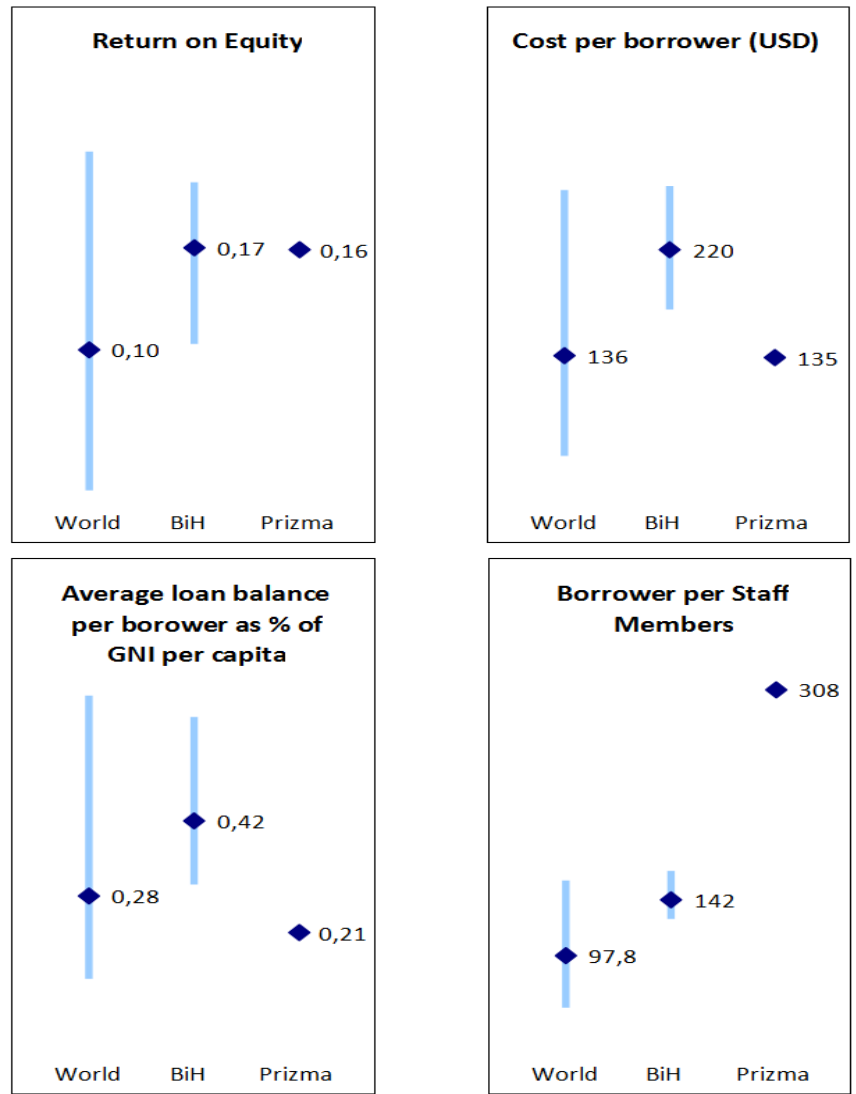

Figure 2. Prizma performance compared to other MCOs in BiH and around the World. Mix Market (values from the 25th and 75th percentiles, with median midpoint).

From its inception, BiH MCOs were efficient and had better results in comparison to other similar institutions around the world. Almost all MCOs in BiH became financially self-sustainable in five to six years' 
time period (see Table 1). Mild variation of certain indicators of financial success in last couple of years was mostly caused by combination of larger costs of financing as a result of pre-orientation on commercial sources of financing and lower interest rates on their loans which was unavoidable in increasingly competitive environment. Figure 2 shows comparison of BiH MCOs with the MCOs around the world, and among them MCO Prizma that performed much better than the rest of the sector measured by key performance based indicators.

Today, microcredit sector in $\mathrm{BiH}$ has all characteristics of a mature MFI sector characterized by high efficiency and stable profitability, lower margin and lower gross income as a result of increased competition compound with stronger pressure from the commercial banking sector.

\section{Social Performance Management in Prizma MCO}

In this section, we will first give a short overview of Prizma MCO. Then, we will turn to analysis of the operationalisation of double bottom line management in Prizma in accordance with the guidelines developed at the beginning of our paper.

\section{Background Information}

Prizma is a private, non-profit distributing microcredit foundation registered in accordance with the Law on Microcredit Organizations. With seed capital from the United Nations and the U.S. government in a form of grants, Prizma began operations in 1997. Today, total capital of Prizma is consisted of donated capital is in amount of 10.4 million of KM and retained earnings in amount of 11 million of KM, which are reinvested exclusively into credit operations. Based on demonstrated financial performances, which are more than evident in mentioned retained earnings and all key performance based indicators, Prizma secures additional funding for further expansion in form of commercial loans from most respectful investors such as EBRD, Credit Suisse and Deutsche Bank.

At the end of 2008 Prizma is a leading poverty focused Microcredit Foundation by the number of clients in $\mathrm{BiH}$ with outstanding gross portfolio of 73 million of KM (\$ 53 million). Prizma has seven branch offices and 37 satellite offices, from which 200 experienced staff members serve over 60,000 active clients. Sixty five percent of Prizma's clients are women and $46.0 \%$ from rural areas.

Prizma offers nine loan products grouped into four segments (i.e., enterprise, agriculture, basic needs and shelter) and employs two lending methodologies to deliver these products: group solidarity and individual. Prizma targets low-end poor, predominantly female clients. For the long time period enterprise loans represent Prizma's core products, comprising about 64\% of all loans issued in 2004. However, in last few years there has been a trend towards diversifying products targeted to rural clients. Portfolio disbursements by loan product at the end of 2008 are given in the Figure 3.

In past three years, Prizma has been working on developing few sophisticated tools for measuring social impact. Manuals and policies have been revised to be more in line with its social mission. Prizma worked a lot on implementing the highest transparency standards. The result was CGAP transparency award three years in a row. Planet rating has rated Prizma with A-, with stable trend, and tested CERISE methodology among the first institutions in the world.

\section{Strategy for Social Performance Management}

Prizma's vision is to be widely recognized for giving people choices to improve their lives and building 
committed respectful relationships. Its mission is to improve the well-being of large numbers of poor women and their families by providing long-term access to quality financial services. Prizma work predominantly with women clients because they make disproportionately large percentage of poor and have weaker possibility to access to formal employment and financial services. However, Prizma does not exclude men, particularly those that are poor.

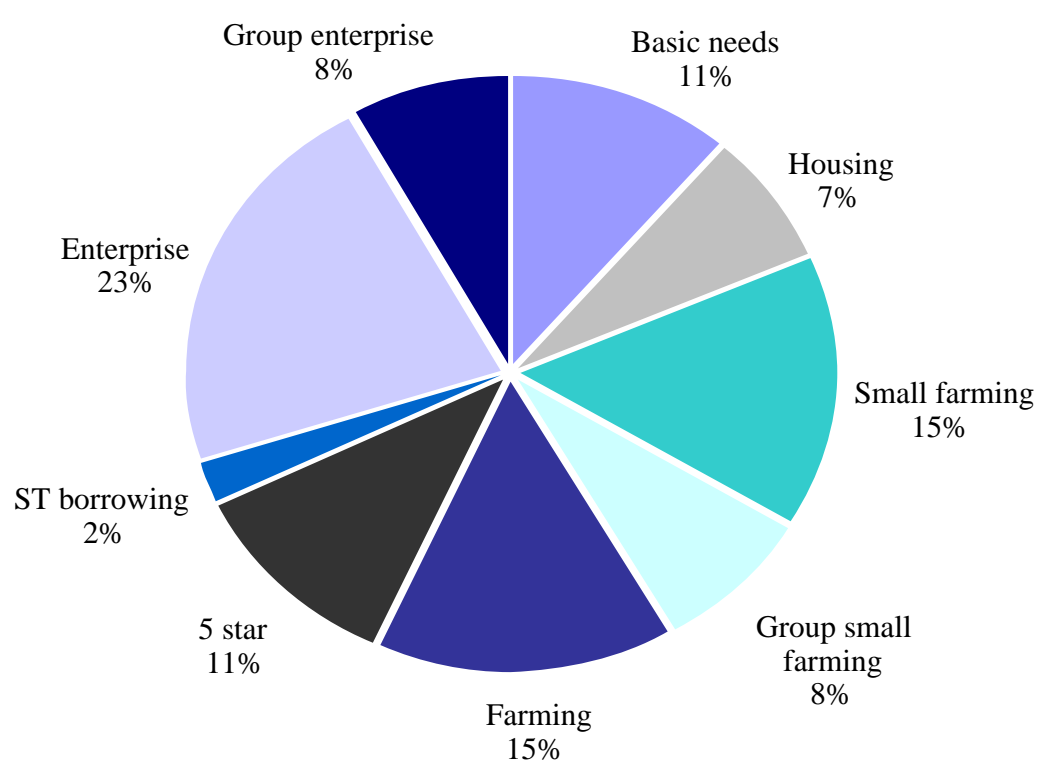

Figure 3. Portfolio disbursement by loan products. MCO Prizma Internal data.

Prizma's mission statement contains the following social goals:

- To strengthen impact-“improve the well-being”;

- To deepen outreach——of large numbers of poor women and their families";

- To ensure the quality of services- “by providing long-term access to quality financial services".

The third goal "to provide long-term access to quality financial services" best demonstrates how closely social and financial performance are linked.

On the basis of these three broad statements of intent, Prizma defined several social performance objectives that allowed the organization to set the performance targets as outlined in Table 2.

In order to define best strategy for reaching social goals, Prizma has sought to employ qualitative and quantitative research methods and draw on available external research to better understand who is poor in this post-war and transitional setting country was facing. This was also necessary in order to answer the question to what extent the organization is reaching these people.

These findings has helped Prizma to better understand its target market and to develop more effective strategy how to reach this market and how to build the product that can help the organization to realize its first objective, "to reduce the poverty level of clients and their families". Prizma seeks to develop the products that can help its clients to:

- Reduce chronic poverty — by helping to create and sustain employment among the economically active poor and low-income people; 
- Reduce transitory poverty—by providing financial services that enable clients to reduce income fluctuations as a result of intermittent pension payments, variable remittances, and unforeseen setbacks to business activity and family stability;

- Reducing the risk of becoming poor-by providing financial services that strengthen livelihoods, increase the level and regularity of incomes, and help mitigate vulnerability where state social services are inadequate or non-existent.

Table 2

Social Goals and Social Performance Objectives

\begin{tabular}{|c|c|c|c|c|}
\hline Mission & Social goals & $\begin{array}{c}\text { Social performance } \\
\text { objectives }\end{array}$ & $\begin{array}{c}\text { Performance target in } \\
\text { strategic/operational plans }\end{array}$ & $\begin{array}{l}\text { Specific incentive } \\
\text { system in place }\end{array}$ \\
\hline \multirow{6}{*}{$\begin{array}{l}\text { To improve the } \\
\text { well-being of large } \\
\text { numbers of poor } \\
\text { women and their } \\
\text { families by providing } \\
\text { long-term access to } \\
\text { quality financial } \\
\text { services }\end{array}$} & $\begin{array}{l}\text { Improve } \\
\text { clients' well-being }\end{array}$ & $\begin{array}{l}\text { Reduce the poverty level } \\
\text { of clients and their } \\
\text { families over time }\end{array}$ & $\begin{array}{l}\text { Under development will give } \\
\text { target number for changes in } \\
\text { poverty status through the loan } \\
\text { cycles. }\end{array}$ & \\
\hline & \multirow{3}{*}{$\begin{array}{l}\text { Serve poor } \\
\text { Clients }\end{array}$} & \multirow{3}{*}{$\begin{array}{l}\text { To deepen outreach to } \\
\text { poor clients }\end{array}$} & $\begin{array}{l}\text { Performance target indicating } \\
\text { number of clients is set and } \\
\text { revised annually. }\end{array}$ & $\begin{array}{l}\text { Loan officers are } \\
\text { monthly rewarded } \\
\text { progressively for } \\
\text { achieving }>25 \%,> \\
40 \% \text {, or }>60 \% \text { of } \\
\text { new clients who are } \\
\text { poorr (below } \\
\text { national poverty } \\
\text { line-score } 0-2 \text { ). }\end{array}$ \\
\hline & & & $\begin{array}{l}\text { Performance targets that are } \\
\text { related to the poverty level and } \\
\text { poverty status of clients is under } \\
\text { development-will give target } \\
\text { number for the percent of new } \\
\text { client who are poor (bellow the } \\
\text { national poverty line-score } \\
\text { 0-2) and for the percent of new } \\
\text { client who are vulnerable but } \\
\text { not poor (slightly above the } \\
\text { national poverty line-score } \\
3-5 \text { ). }\end{array}$ & $\begin{array}{l}\text { Each branch team } \\
\text { is annually } \\
\text { rewarded } \\
\text { progressively for } \\
\text { achieving }>25 \% \text {, > } \\
40 \% \text {, or }>60 \% \text { of } \\
\text { new clients who are } \\
\text { poor } \quad \text { (below } \\
\text { national poverty } \\
\text { line-score } 0-2 \text { ). }\end{array}$ \\
\hline & & & $\begin{array}{l}\text { Performance target related to } \\
\text { the number of women clients is } \\
\text { also set annually and for } 2007 \\
\text { there are at least } 70 \% \text { of clients. }\end{array}$ & $\begin{array}{l}\text { Performance target } \\
\text { related to the } \\
\text { number of clients is } \\
\text { set as the rule. }\end{array}$ \\
\hline & \multirow[b]{2}{*}{$\begin{array}{l}\text { Provide quality } \\
\text { financial } \\
\text { services }\end{array}$} & Reduce client exit rate & $\begin{array}{l}\text { Keep the exit rate below the } \\
40 \% \text {-revised annually but not } \\
\text { changed in last several years. }\end{array}$ & $\begin{array}{l}\text { Loan officers are } \\
\text { rewarded } \\
\text { progressively for } \\
\text { achieving < } 30 \% \\
\text { monthly exit rates. }\end{array}$ \\
\hline & & $\begin{array}{l}\text { Increase } \\
\text { satisfaction }\end{array}$ & $\begin{array}{l}\text { No satisfaction target, but } \\
\text { regular qualitative assessment } \\
\text { (two times a year). }\end{array}$ & $\begin{array}{l}\text { Each branch team } \\
\text { as well as } \\
\text { headquarter staff is } \\
\text { annually rewarded } \\
\text { progressively for } \\
\text { achieving }<45 \%,< \\
40 \% \text {, or < } 30 \% \\
\text { annual exit rates. }\end{array}$ \\
\hline
\end{tabular}

This multidimensional understanding of poverty in Bosnia and Herzegovina had great impact on how Prizma has defined its target market as well as on developing of new products. For example, poverty score card 
enable Prizma to divide its clients to three different target groups:

- High target group—clients from families that live below the poverty line-poverty score from 0 to 2;

- Standard target group—clients from vulnerable but not poor families that live between $100 \%$ and $150 \%$ of country poverty line-poverty score from 3 to 4 ;

- Non-target group—clients from non poor families.

With the implementation of poverty scorecard, the process of evaluation of potential clients is fully automatized. Poverty score is used together with other information as credit history and guarantees in process of evaluation of potential clients.

\section{Information System in Prizma}

Following from its mission, Prizma has embarked on a number of client assessment activities under the auspices of the "Imp-Act Project". These activities include social performance assessment as well as market research activities such as collecting information on client exit and client's needs and wants aimed at improving its social performance.

Today, Prizma’s SPM information system consists of five core components:

- Monitoring poverty outreach for all clients on entry using poverty score card;

- Monitoring the change of poverty status comparing the each client poverty score on entry with the same information gathered at the start of each repeat loan cycle;

- Exit monitoring, using a short, semi-structured interview, conducted by field staff twice a year to answer the questions such as: Who leaves? What is the magnitude? What are the characteristics of dropouts? Why do they leave?;

- Client satisfaction monitoring, conducted by marketing manager twice a year;

- Focus groups discussions that enable Prizma to investigate the reasons behind the patterns and trends in clients' status highlighted by the monitoring data.

Due to page limitation of this paper we have focused ourselves only on most important social performance tools, in our case poverty score card and exit monitoring system.

\section{Poverty Scorecard $^{7}$}

Working with MFC under Imp-Act, Prizma developed a poverty assessment system intended to measure poverty status of its clients and to monitor change in poverty status over time. This system enables the Prizma to rank its clients by relative poverty, and across different segments of its clientele. These ranks can help managers to better understand who is being served. Also, it enables the organization to report on clients' poverty status in absolute terms, in relation to the national poverty line and the international poverty benchmark of \$1 and \$ 2 a day. Finally, it enables the organization to measure discrete change in clients’ poverty status and well-being over time. While this approach does not assume attribution, measuring change in household poverty status over time does provide important signal on which to make inferences about outcomes of medium- to long-term service provision and highlight areas for further investigation.

Poverty scorecard is a composite measure of household poverty based on some of the strongest and most

\footnotetext{
${ }^{7}$ More information on Prizma's poverty scorecard you can find in Schreiner, Matul, Pawlak, and Kline (2005) and Matul and Kline (2003).
} 
robust non-income indicators proxies for poverty in Bosnia and Herzegovina. The scorecard is comprised of seven non-expenditure indicators. The first three-education level, residence, and household size-reflect poverty risk categories. If the household head has primary level of education or less, or if the household live in the rural area of the country or if the household have six or more members, the likelihood that the household is poor increases significantly. The second four indicators-household assets, transport assets, meet consumption and sweets consumption - measure change in household poverty status while contributing to the poverty risk profile of each new or renewal applicant's household, also enable Prizma to measure change in poverty status, or well-being, over time (see Figure 4).

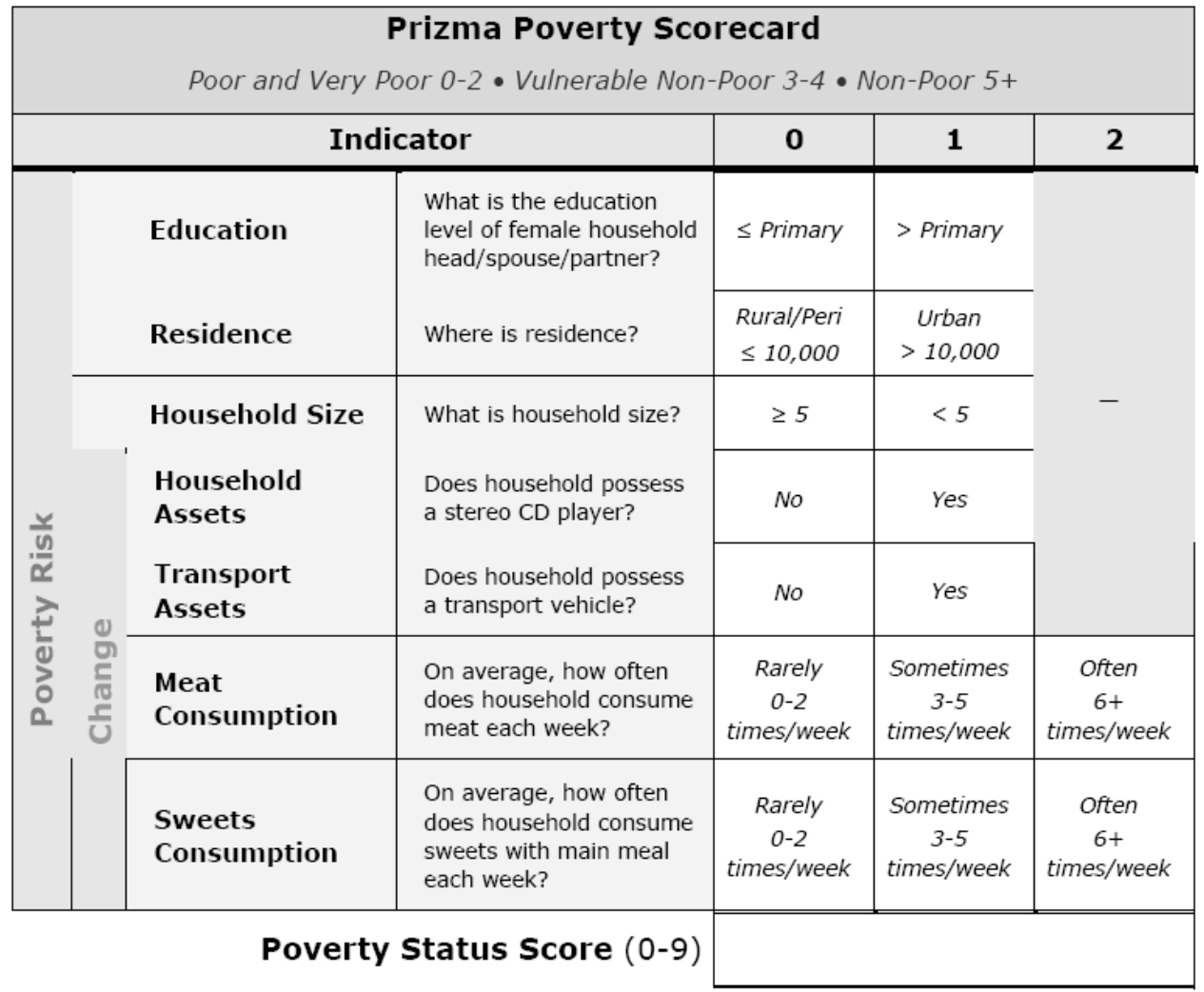

Figure 4. Prizma poverty scorecard.

Each client score can range from 0 (most likely poor) to 9 (last likely poor). Within this overall range, three ranges have been defined that correspond to the poverty categories outlined (see Table 3).

Table 3

Three Ranges of the Poverty Categories

\begin{tabular}{|l|l|l|}
\hline \multicolumn{1}{|c|}{ Range } & \multicolumn{1}{|c|}{ Score } & \multicolumn{1}{c|}{ Introduction } \\
\hline Poor and very poor & Score $0-2$ & Living below the LSMS poverty line. \\
\hline Vulnerable non-poor & Score 3-4 & Living between 100\%-150\% of LSMS poverty line. \\
\hline Non-poor & Score 5+ & Living above $150 \%$ of LSMS poverty line. \\
\hline
\end{tabular}

Using these three ranges, Prizma can rank all its clients by relative poverty. For example, a household that has a composite score of two can clearly be said to be poorer than a household that has a score of four. Relative 
scores can be translated into absolute measures by linking score ranges to the LSMS General Poverty Line. Prizma's overall poverty rate is its clients' average poverty likelihood. The average poverty likelihood is the share of cases with a given score multiplied by the associated poverty likelihood, summed for all scores. Prizma's poverty rates calculated during the testing period are close to the national poverty rate of 19.3 percent. It is hard to say that this poverty outreach is high or low, because we do not know poverty outreach that is sustainable or poverty outreach of other micro-lenders in BiH. Poverty rates can also be analyzed by loan product and by branch. This is very useful considering the fact that this gives Prizma an insight which of its loan products is best adopted to its target clients' needs.

Conducted analysis in last few years has shown that poverty outreach data varied more by branch than by loan product, perhaps highlighting the importance of branch placement and branch managers' outreach within their service areas. Also, newer/smaller/non-growing branches (those that had fewer new clients during the testing period) had lower concentrations of poverty, perhaps because older/larger/growing branches face more pressure (or are more able, due to their experience) to go beyond less-poor clients.

Enabling staff to generate reports on client household poverty status by branch, product, dropout, gender, portfolio quality, and an array of other variables, poverty scorecard is going to represent a milestone in Prizma's future efforts to enhance social performance. In addition to enabling the institution to better meet its developmental imperatives, this system is enabling Prizma to meet critical institutional imperatives, including:

- Depth of outreach and change in client status are incorporated into the institution's incentive system to motivate staff and affirm the primacy of social performance which helps in managing human resources;

- Monitoring client dropout by poverty status enables the institution to better understand the appropriateness of its service and what can be done to retain and help these clients;

- Developing products and services that meet the development needs of poor clients;

- Positioning the organization strategically through developing more effective promotion strategies and delivery channels to attract, serve, and retain its target clients;

- Integrating poverty scoring data into Prizma's activity-based costing (ABC) system help the organization to better understand its cost structure of its products and locus of cost associated with outreach to poorer clients that enables the institution to identify means to provide more efficient service.

Poverty scoring data Prizma can be used to enhance its understanding of credit risk to further deepen its outreach.

\section{Exit Monitoring System ${ }^{8}$}

In order to better understand and address client exit, a phenomenon that is costly to Prizma's bottom line of achieving sustainability $^{9}$ and its effort to achieve sustained social impact over time, Prizma together with MFC has designed an exit monitoring system (EMS). This valuable tool verifies if its services and procedures meet different target clients' needs, revealing areas for improvement. EMS provides Prizma's different users with timely answers to the questions such as: Who is leaving? What is the magnitude? What specific group are leaving? EMS is also helping the organization to be more realistic in designing a retention bonus system.

\footnotetext{
${ }^{8}$ For more information on Prizma’s exit monitoring system see Matul and Vejzovic (2004).

9 An Activity Based Costing exercise showed that Prizma invests a lot in its first-cycle clients. If these clients leave the institution, Prizma loses money.
} 
Prizma has made distinction between voluntary and "forced-out" drop-outs ${ }^{10}$. Voluntary drop-outs are further disaggregated to satisfied (reasons not related to Prizma) and dissatisfied (Prizma-related reasons). Table 4 sums up the general drop-out categories Prizma has agreed to monitor.

Prizma has decided to sample drop-outs randomly, not excluding any drop-out client from the list. Prizma EMS is based on the semi-structured interview. The first part of the interview is an in-depth investigation of different reasons for client drop-out (dissatisfaction with Prizma services, external reasons, repayment problems, etc.). At the end of the first part, the interviewer summarizes the two main exit reasons with the respondent. The second part is devoted to the current use of financial services by the ex-client, competition analysis, and his/her intent to take another loan in Prizma. Upon completion of the interview the loan officer (LO) classifies the drop-out according to the nature of his/her reasons, current use of other financial services, and intent to take an additional loan to achieve the main profile of the drop-out (see Figure 5).

Table 4

The Main Drop-Out Profiles

\begin{tabular}{|l|l|}
\hline \multicolumn{1}{|c|}{ Type of drop-out } & \multicolumn{1}{c|}{ Core follow-up questions to be considered } \\
\hline $\begin{array}{l}\text { Voluntary_satisfied } \\
\text { (reasons not related to Prizma) }\end{array}$ & $\begin{array}{l}\text { - Forever or “asleep”? } \\
\text { - Can microfinance assist in solving their problems? } \\
\text { - Loyal or not? }\end{array}$ \\
\hline $\begin{array}{l}\text { Voluntary_dissatisfied } \\
\text { (Prizma-related reasons) }\end{array}$ & $\begin{array}{l}\text { - Forever or “asleep”? } \\
\text { - Dissatisfaction factors? } \\
\text { - Went to competition? } \\
\text { - Will come back if services improved? }\end{array}$ \\
\hline Forced out & $\begin{array}{l}\text { - Bad character or bad services? If later, what should be adjusted? } \\
\text { - Went to competition? }\end{array}$ \\
\hline
\end{tabular}

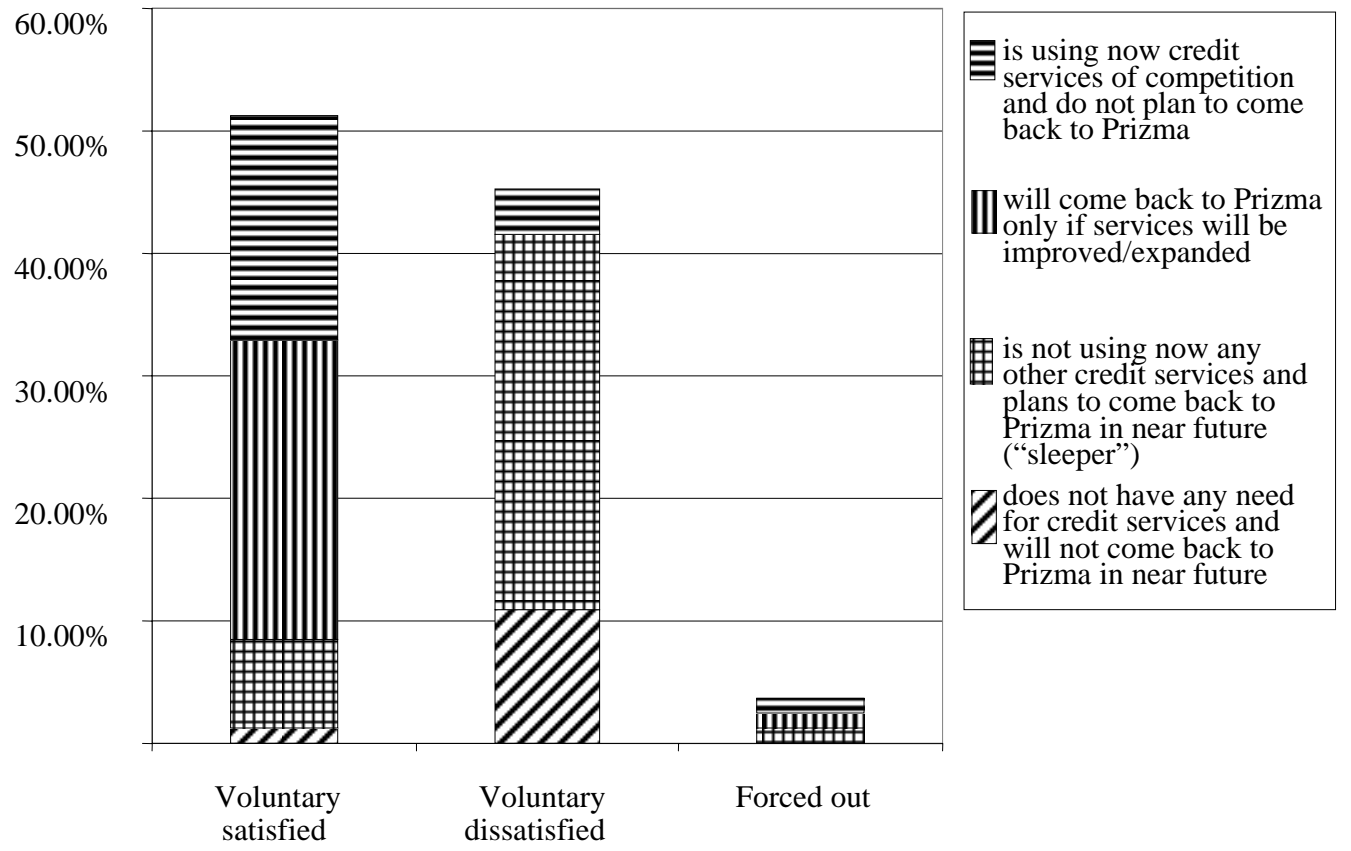

Figure 5. Cross tab (main reasons/behaviors).

\footnotetext{
10 The forced-out drop-outs are those who are expelled by an institution or, in the case of group lending, by other group members because they did something that suggests that they may be a bad credit risk.
} 
While monitoring the profiles by different breakdowns provides a valuable information for management, it is difficult to act on such an aggregated piece of information without knowledge about the exit reasons for specific groups of clients. In Prizma case more sophisticated reporting is possible with breakdowns by variables such as last product type used, use of multiple services, loyalty level (length, breadth, depth), seasonality, repayment performance, business, household, individual (demographic) characteristics, loan use. However, since activities on poverty scoring just started, it is not possible to make breakdown according to poverty status, the most important from the SPM perspective.

\section{Aligning the Systems and Structures to SPM}

Prizma has undertaken some important steps in aligning the organizational systems and structures to its SPM goals (see Figure 6). Organizational culture was of fundamental importance for these processes. Key contributions come from senior management who has taken important steps to communicate and reshape the culture to balance developmental and institutional objectives. Management has revised and strengthened the recruitment and induction process to ensure mission, vision, and organizational values are central to every applicant and employee's introduction to and training within Prizma. Management then affirms mission and values on an ongoing basis via the organization's intranet, memos, annual retreat, and regular office visits. Also, it has been clear from Prizma's inception that communicating branch, product, and organization-wide performance results to staff on a regular basis yields accountability for results and strong consequent performance.

To include even more members of the board in SPM activities and ensure their support on this road in 2007 Prizma formed Social Performance Committee. Prizma's general strategy is to integrate SPM in its every day operations, not to have special SPM department. However, currently in Prizma there is special SPM team that coordinates the SPM process and is actively working on applying a poverty lens to all formal documentation, adding to or revising where there were opportunities to reframe Prizma's operations-methodology, policies, and procedures—in terms of targeting, attracting, serving, and retaining poor people.

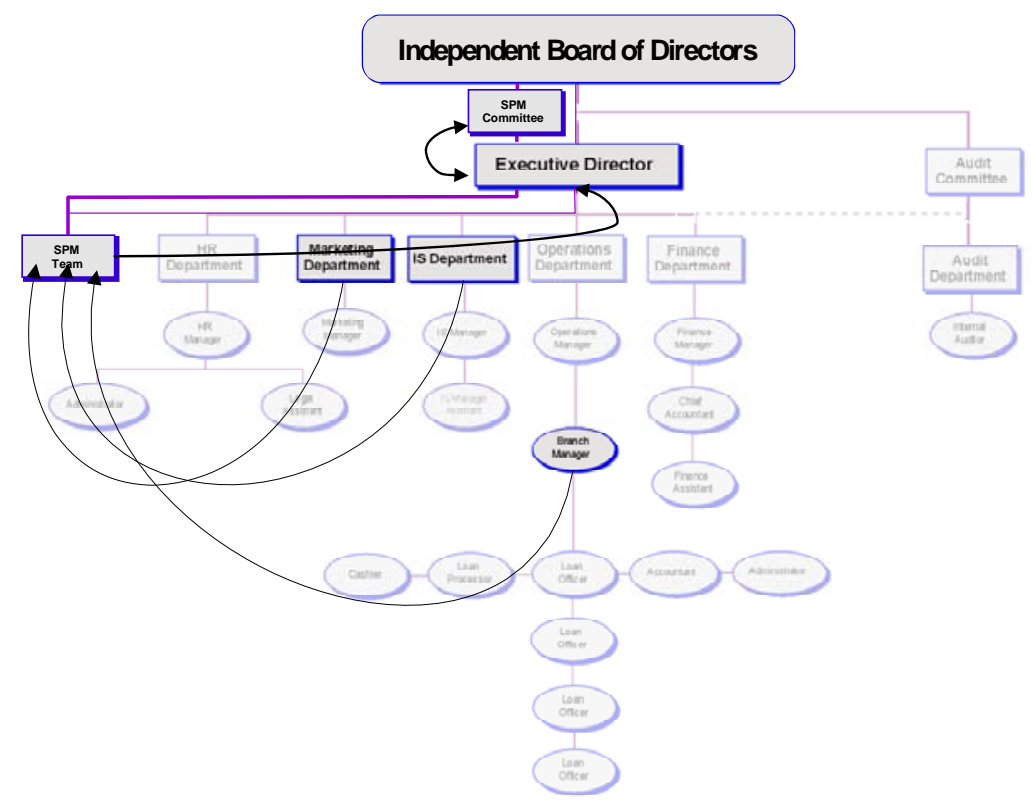

Figure 6. Prizma’s organizational structure. 
Key points where Prizma has taken steps to enhance and institutionalizes social performance have been in re-engineering its performance management system-appraisal, reward, and communication - to better align employee interests and reward with greater depth of outreach, improved service quality, and the financial health of the institution. On one level, loan officers are rewarded monthly for performance on a few select indicators, including those in four of Prizma's six core performance areas (see Figure 7). This monthly incentive focuses on short-term social and institutional performance. On a second level, each member of each branch team receives a percentage of Prizma's annual surplus as a flat profit share based on their team's aggregate score across its six core performance areas.

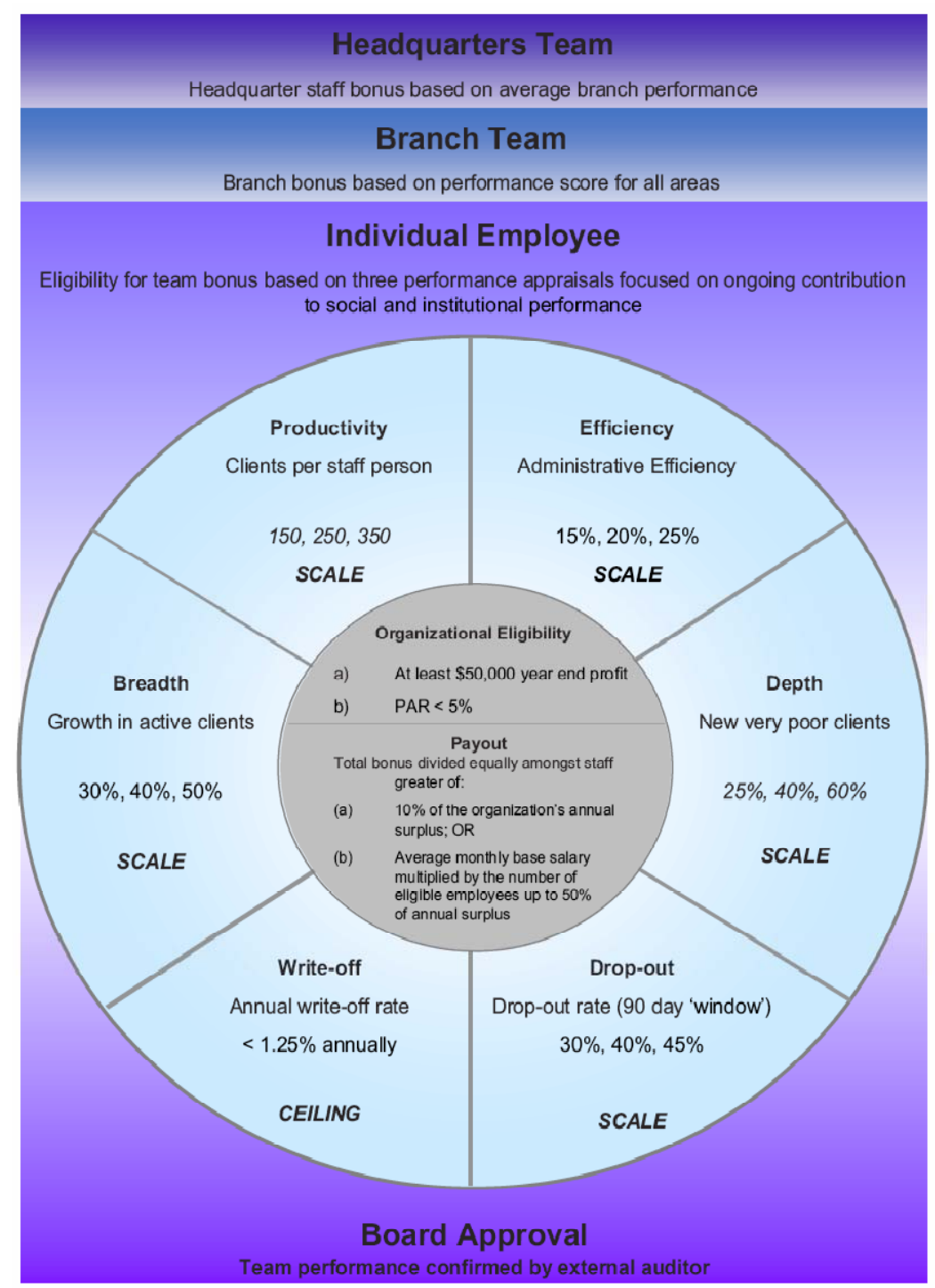

Figure 7. Appraisal system in Prizma.

Rather than a reward for short-term results, this incentive affirms strong team performance towards the organization's social and institutional objectives on an annual basis. Affirming the fundamental role of headquarters to facilitate branch and, in turn, client success, each member of the headquarters team is rewarded 
based on the performance of the branch network overall, if those in the field succeed, headquarters is rewarded. Figure 7 summarizes eligibility at each level and the six core performance areas on which the bonus is based. Among other benefits, this new system has contained personnel costs by tying them more closely to Prizma's financial health; increased the regularity, consistency, and relevancy of formal performance appraisal (now every trimester); clarified what good performance is for every position at every level; balanced reward for individual and team performance; balanced short and medium term performance; and helped maintain focus on sustaining social performance.

\section{Cost and Benefit of SPM}

In this part of the case study, we will give short overview of the costs involved in different client assessment activities. To calculate the costs of the three client assessment activities, members of Prizma's management team, loan officers, and the lead consultant from the MicroFinance Centre (MFC) who advised Prizma on each of the three client assessment activities were interviewed. The purpose of the interviews was to identify the level of effort (days and hours worked) invested by each participant in each step in the client assessment process for each of the three activities examined as well as expenditures on supplies and logistics. Of course, these cost estimates should be considered ballpark estimates rather than precise point estimates.

As you can see from the Table 5, overall costs attributable to scorecard development are estimated at $\$ 21,692$. The costs attributable to development of the exit monitoring system are estimated $\$ 6,605$, and costs attributable to FGD development and implementation are estimated to $\$ 13,759$. The total cost for all three client assessment activities is thus estimated to be around \$42,000.

Table 5

Overall Costs of Different Client Assessment Activities

\begin{tabular}{lc}
\hline Client assessment activity & Overall development costs $(\$)$ \\
\hline Poverty scorecard & 21,692 \\
Exit monitoring system & 6,605 \\
Focus group discussions & 13,759 \\
Total & 42,056 \\
\hline
\end{tabular}

In 2004, using activity-based costing (ABC) data, Gary Woller calculated that Prizma would need to retain 78 clients (1.1 percent of clients) for one loan cycle to cover the costs of the poverty scorecard, 24 clients (0.4 percent of clients) for one loan cycle to cover the costs of the EMS and 50 clients ( 0.7 percent of clients) for one loan cycle to cover the costs of the FGDs (Woller, 2004). These figures translate into a fall in Prizma's weighted average drop-out rate from 44.4 percent to 42.2 percent to cover all client assessment costs; to 43.3 percent to cover the costs of the poverty scorecard; to 44 percent to cover the costs of the EMS; and to 43.7 percent to cover the costs of the FGDs.

For each of the three assessment activities, overhead costs can be expected to be significantly lower for successive implementation rounds given that the initial phase included substantial technical assistance and planning and training costs, many of which were one-offs. Finally, as Prizma's management and staff move up the learning curve, implementation efficiency is expected to increase, driving the variable costs down further, thereby increasing the net benefits of client assessment accordingly. According to Prizma's estimations, the 
monthly costs of ongoing activities related to SPM (training, loan operations, compiling and writing reports, and internal auditing) are approximately 1,200 Euros.

All the above explained SPM activities had strong impact on Prizma's continuous down market focus and fulfillment its mission objectives. Maybe this is the best seen through the analysis of the trend in outstanding balance from 2002 to 2008 among the biggest MFIs in Bosnia and Herzegovina. We can see a slight increase in the average outstanding balance for all MFIs but also that Prizma's balance is much lower compared to its competitors (see Figure 8).

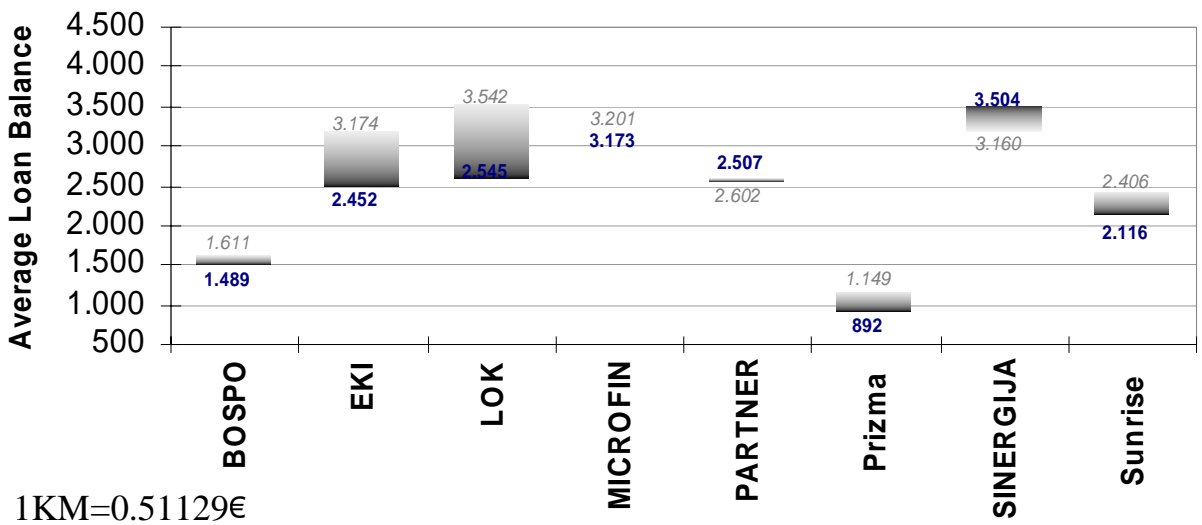

Figure 8. Change in average outstanding balance 2002-2008. Bold denotes 2002 average outstanding balance in KM.

Down-market focus brings Prizma some important benefits. Operating in a niche market where competition is weaker allows it to increase its productivity and efficiency. The number of loans per loan officer in 2008 was 464 compared to the industry average of 262 (see Figure 9).

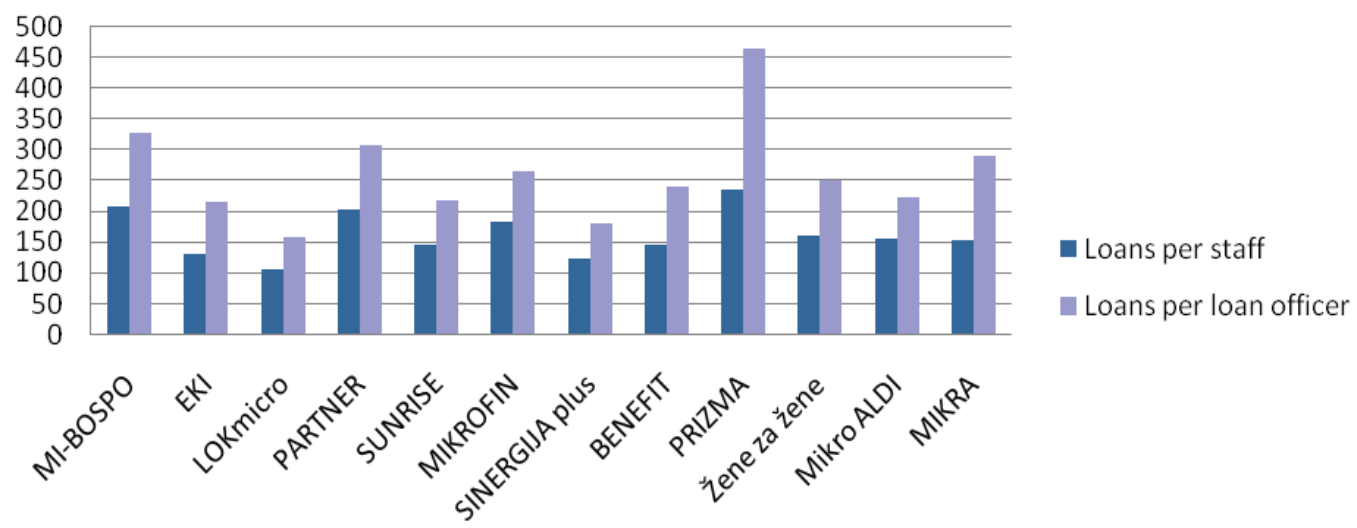

Figure 9. Loans per staff and officer in different MCOs.

Finally, the cost per loan disbursed (210 KM at the end of 2008) is much lower than the industry average (362 KM).

\section{Concluding Remarks}

Social performance is commonly defined as "effective translation of an institution's social goals into practice in line with accepted social values”. This definition emphasizes that in doing social assessment, it is 
necessary to look at the entire process that has to be anchored in the institution's mission and systematically leads to changes in the client's status. This process starts with the institution's mission, and social goals. The second step includes the assessment of whether the institution's internal systems and activities are appropriate and aligned with the achievement of its declared social objectives. The next step regards the output. Is the institution reaching its target clients? Are products designed to meet the clients' needs and in line with their capacities? The fourth step is about outcome achieved. Are the clients improving their economic and social performance? The final step in the process is related to the impact-establishing causality between the program participation and improvements in the clients' condition. The process, of course, has to be iterative. Information about the achieved outcome has to be used in decision-making that eventually improve performance and practice.

In this paper, using the example of Prizma MCO, we have conducted in-depth analysis how the different steps in the process of achieving the change can be practically implemented. What are potential costs and benefits? We will conclude the paper with the specification of major challenges in this process and some of the lessons learned that may be used in all other industries.

First, and maybe the most important conclusion is that example of Prizma MCO clearly shows that it is possible to manage the double bottom line, that is, to balance successfully in a long term financial and social objective. SPM is good and essential for business given that it can make or break institution's competitive position, image, client and staff loyalty and ultimate financial returns and performances such as profits, share holding values etc..

Second conclusion is that it takes time and efforts to build systems, integrate them in standard operating procedures and build around them a strong and cohesive organizational culture that embraces CSR by communicating over and over again as to why it is good and important for all, however, the companies should never accept a short term solution for a long term problem.

Investing in CSR should be considered as a sound business decision and good investment rather than as a cost. Because of this, in building effective SPM it is of extreme importance to have strong support from senior management. This is necessary to ensure the communication line from top to bottom of the organization. This is also because still there is no best SPM practice organization can follow, and sometimes it faces trade-off between social and financial goals. The last, but not the least SPM operationalization means investments today, and eventually the organization will bear the fruits sometime in the future.

What is also important is that the organization must ensure staff buy-in. A lot effort has to be put to make them understand the purpose of the whole process and try to include them as much as possible in planning and discussing necessary institutional changes. In addition, organization should introduce explicit support for staff performance that leads to greater poverty outreach by introducing or adapting existing incentives for outreach to poor people to affirm that outreach to poor people is both valued and rewarded.

Next conclusion is that organization needs to appoint the leaders of the whole process that coordinate the SPM activities and act as its advocate. There are two reasons for this. First of all, implementation of SPM is multidisciplinary process which involves coordinated action of different functions in organization. Additionally, SPM operationalization implies permanent changes in an organization applying a poverty lens to all formal documentation, adding to or revising where there were opportunities to reframe methodology, policies, and procedures in terms of targeting, attracting, serving, and retaining poor people. 
The ultimate conclusion might be that operationalizing social performances-meaning, integrating them in standard operating procedures at all levels and functions of an organization day to day work is the most effective long-term approach in managing double-bottom line for every single institution, company and/or state in the world.

\section{References}

AMFI. (2009). AMFI annual report for 2008. Association of Microfinance Institutions in Bosnia and Herzegovina, Sarajevo.

Bhattacharya, C. B., Sen, S., \& Korschun, D. (2008). Using corporate social responsibility to win the war for talent. MIT Sloan Management Review, 49(2), 37-44.

Drucker, P. F. (2007). The essential drucker. Oxford, UK: Elsevier.

Friedman, M. (1970, September 13). The social responsibility of business is to increase its profits. The New York Times Magazine.

Halilbasic, M., \& Crnkic, K. (2007). Microfinance in Bosnia and Herzegovina. Collection of papers, Sarajevo School of Economics and Business, 27, Sarajevo.

Hashemi, S. (2007). Beyond good intentions: Measuring the social performance of microfinance institutions. CGAP Focus Note No. 41.

Kytle, B., \& Ruggie, J. G. (2005). Corporate social responsibility as risk management: A model for multinationals. Social Responsibility Initiative Working paper No. 10. Cambridge, M.A.: John F. Kennedy School of Government, Harvard University.

Matul, M., \& Kline, S. (2003). Scoring change: Prizma’s approach to assessing poverty. MFC Spotlight Note 4.

Matul, M., \& Vejzovic, S. (1994). Beyond numbers: Prizma’s exit monitoring system. MFC Spotlight Note 10.

Norman, W., \& MacDonald, C. (2003). Triple bottom line: A critique. Retrieved March 7, 2009, from http://www.businessethics.ca/3bl

Saether, K. T., \& Ruth, V. A. (2008). Corporate social responsibility in a comparative perspective. In A. Crane, et al. (Eds.), The Oxford handbook of corporate social responsibility. Oxford: Oxford University Press.

Schreiner, M., Matul, M., Pawlak, E., \& Kline, S. (2005). The power of Prizma’s poverty scorecard: Lessons for microfinance, microfinance $\quad$ risk management. Retrieved from http://www.microfinance.com/English/Papers/Scoring_Poverty_in_BiH_Long.pdf

SEEP. (2007). Social performance progress, 1(3). Brief. Retrieved from http://www.seepnetwork.org/content/library/detail/5150

Shina, F. (2007). Social rating and social performance reporting in microfinance: Towards a common framework, argidius foundation. Retrieved from http://www.m-cril.com/pdf/Framework-for-Social-Performance-Rating-and-Reporting.pdf

Woller, G. (2004). The cost-effectiveness of social performance assessment: The case of Prizma in Bosnia-Herzegovina. Small Enterprise Development, 15(3), 41-51(11).

Wood, D. (1991, October). Corporate social performance revisited. The Academy of Management Review, 16(4). 